\title{
Conformers, Vibrational Spectra and Infrared-induced Rotamerization of Dichloroacetic Acid in Argon and Krypton Matrices
}

\author{
Anatoly Kulbida \\ Institute of Physics, St. Petersburg University, Peterhof, 198904 St. Petersburg, Russia \\ Rui Fausto* \\ Department of Chemistry, University of Coimbra, P-3049 Coimbra, Portugal
}

\begin{abstract}
The results of a combined study of dichloroacetic acid monomer undertaken by matrix-isolated low-temperature infrared spectroscopy in both argon and krypton matrices and ab initio SCFMO calculations are presented. Two $s$-cis $(\mathrm{C}-\mathrm{O})$ conformations of $\mathrm{CCl}_{2} \mathrm{HCO}_{2} \mathrm{H}$ differing by internal rotation about the $\mathrm{C}-\mathrm{C}$ bond and one $s$-trans form were found in the matrices. Their spectra are reported within the range $4000-400 \mathrm{~cm}^{-1}$ and interpreted. The skew/s-cis form $\left(\mathrm{H}-\mathrm{C}-\mathrm{C}=0\right.$ dihedral angle equal to $\left.\mathrm{ca} .144^{\circ}\right)$ converts to the most stable syn/s-cis conformer $\left(\mathrm{H}-\mathrm{C}-\mathrm{C}=\mathrm{O}: 0^{\circ}\right)$ upon irradiation in the $v(\mathrm{O}-\mathrm{H})$ region. The temperature dependences (annealing) of the isolated matrix vibrational spectra of the studied molecule before and after irradiation were found to be different, and a model is proposed to explain the experimental observations.

In addition, 3-21G and 6-31G* $a b$ initio- $M O$ calculations were carried out and the structures and energies of the relevant conformations are reported. The theoretical results agree with the experimental data and provide a good insight into the intramolecular interactions which determine the relative stability of the various conformers. Finally, a normal-mode analysis based on the 6-31G* harmonic force fields is used to review previous assignments of the vibrational spectra of the various conformers of the studied molecule.
\end{abstract}

In a previous work, ${ }^{1}$ we studied the rotamerization of $\mathrm{CH}_{2} \mathrm{ClCO}_{2} \mathrm{H}$ in an argon matrix. Three different conformers have been found in the non-annealed matrix: the $s y n / s$-cis (SC), skew/s-cis (SKC) and anti/s-trans (AT) forms (see Fig. 1), with relative populations of 60,25 and $15 \%$, respectively. Irradiation of the matrix in the carbonyl stretching $[v(\mathrm{C}=\mathrm{O})]$ region by a $\mathrm{CO}$ laser causes conversion of the most stable SC rotamer to both less stable forms. ${ }^{1}$ Later on, the relative energies, equilibrium molecular geometries and vibrational force fields of the $\mathrm{CH}_{2} \mathrm{ClCO}_{2} \mathrm{H}$ conformers were obtained by $a b$ initio $6-31 \mathrm{G}^{*}$ SCF MO calculations; ${ }^{2}$ the theoretical results enabled us to improve the previous empirically based assignments of the vibrational spectra of the (a)<smiles>[X]C([Y10])([Y10])C(=O)O</smiles>

(b)<smiles>[Y10]C([Y4])([Y4])C(=O)O</smiles>

(c)<smiles>[Y10]C([Y10])([Y10])C(=O)O</smiles>

(d)<smiles>[Y]C([Y10])([Y10])C(=O)O[3H]</smiles>

$(\theta)$<smiles>[Y4]C([Y10])([Y10])C(=O)O</smiles>

Fig. 1 Relevant conformations of chloroacetic and dichloroacetic acid molecules. $\mathrm{X}, \mathrm{Y}=\mathrm{H}$ or $\mathrm{Cl}$ studied molecule $e^{3,4}$ and confirmed the nature of the three conformers experimentally observed.

In the present article, we focus our attention on $\mathrm{CHCl}_{2} \mathrm{CO}_{2} \mathrm{H}$. The rotational isomerism in this molecule was previously studied experimentally by infrared spectroscopy in condensed phases ${ }^{5-8}$ and theoretically by $a b$ initio SCF MO calculations, using the STO-3G minimal basis set, ${ }^{9}$ as well as by molecular mechanics. ${ }^{10}$

There is general agreement between the various studies previously carried out on dichloroacetic acid with respect to the nature of the most stable conformers of this molecule ${ }^{5-12}$ (Fig. 1). Thus, the two most stable forms correspond to the s-cis $(\mathrm{C}-\mathrm{O})$ structures: the symmetric $s y n / s$-cis conformer (SC), where the hydrogen atom of the dichloromethyl group and the carbonyl oxygen are eclipsed, and a doubly degenerated conformer having one of the chlorine atoms of the dichloromethyl group nearly eclipsed with the carbonyl oxygen atom (the skew/s-cis form, SKC). The energy difference between these conformers was predicted to be less than $1 \mathrm{~kJ} \mathrm{~mol}^{-1,5,10,11}$ and the energy barrier for internal rotation about the $\mathrm{C}_{\alpha}-\mathrm{C}$ bond, for a fixed $\mathrm{O}=\mathrm{C}-\mathrm{O}-\mathrm{H}$ s-cis configuration, smaller than $2 \mathrm{~kJ} \mathrm{~mol}^{-1} \cdot{ }^{10}$ In addition, molecular mechanics also predicts the existence of two high-energy conformers of dichloroacetic acid having an s-trans $(\mathrm{C}-\mathrm{O})$ axis, the ST and SKT conformers (see Fig. 1); the energy change associated with the $s$-cis $\rightarrow s$-trans conversion was predicted to be about $33 \mathrm{~kJ} \mathrm{~mol}^{-1} .^{10}$

Despite the knowledge available about the conformational preferences and vibrational spectra of dichloroacetic acid, several important points remain poorly understood. In particular, intramolecular interactions, which determine the relative stability of the various conformers, have not yet been analysed in detail, and the interpretation of the vibrational spectra of the studied molecule requires some theoretical foundations in order to enable accurate spectra-structure relationships to be established. At the same time, it is difficult to carry out an accurate comparison of the $a b$ initio calculated results with those experimentally obtained in $\mathrm{CCl}_{4}$ solution ${ }^{5}$ where the intermolecular interactions with the solvent 
certainly influence the rotamer spectra and energies. On the other hand, the single conformational study previously undertaken on the studied molecule in the gaseous phase could identify only the SKC rotamer bands in its microwave spectrum. ${ }^{12}$ Matrix isolation seems to be a much more suitable method for this purpose.

In addition, we found that irradiation of the matrixisolated $\mathrm{CHCl}_{2} \mathrm{CO}_{2} \mathrm{H}$ in the hydroxy-group stretching region $[v(\mathrm{O}-\mathrm{H})]$ induces rotamerization reactions easily detectable in the infrared spectra, although, unlike $\mathrm{CH}_{2} \mathrm{ClCO}_{2} \mathrm{H},{ }^{1}$ irradiation by a $\mathrm{CO}$ laser is ineffective in this case.

We present the results of a study of dichloroacetic acid undertaken by matrix-isolated low-temperature infrared spectroscopy and ab initio SCF MO calculations.

\section{Experimental and Computational Methods}

The samples were prepared by simultaneous deposition of a matrix gas and $\mathrm{CHCl}_{2} \mathrm{CO}_{2} \mathrm{H}$ jets on a CsI substrate, cooled using an ROK $10-300$ (Leibold-Heraeus) closed-cycle refrigerator. $\mathrm{CHCl}_{2} \mathrm{CO}_{2} \mathrm{H}$ was obtained from Sigma and purified by several freeze-pump-thaw cycles. The $\mathrm{CHCl}_{2} \mathrm{CO}_{2} \mathrm{H}$ beam was led from an effusion cell through a heated thin capillary, where dimer thermolysis took place. The effusion cell temperature was kept constant by a heater so that the matrix : solute ratio was at least equal to 1500 . The rate of the matrix gas flow was ca. $5 \times 10^{-3} \mathrm{~mol} \mathrm{~h}^{-1}$. The amount of $\mathrm{CHCl}_{2} \mathrm{CO}_{2} \mathrm{H}$ deposited was controlled by following the absorbance of the infrared bands at 1153 and 1115 $\mathrm{cm}^{-1}$. Further details on the sample preparation procedure can be found in ref. 1. The deposition temperature were 14 or $18.5 \mathrm{~K}(\mathrm{Ar})$ and 14 or $20 \mathrm{~K}(\mathrm{Kr})$. During both the irradiation and recording of the spectra the matrix temperature was kept constant at $c a .14 \mathrm{~K}$.

The infrared spectra were recorded on a Hitachi $270-30$ spectrophotometer with $2-4 \mathrm{~cm}^{-1}$ resolution. For the rotamerization experiments, the infrared radiation source used was the coiled filament (kanthal wire at $1500^{\circ} \mathrm{C}$ ) of the spectrophotometer or a special monochromator using a 200 $\mathrm{cm}^{-1}$ diffraction grating with a $1: 2$ aperture and the same radiation source. The use of filters and a preliminary monochromator proves that $v(\mathrm{OH})$ absorption is responsible for the observed photoprocess which causes the rotamerization reactions under study. Therefore, a cut-off filter transmitting radiation with frequency $<1950 \mathrm{~cm}^{-1}$ was used for recording the spectra; irradiation in these spectral regions was found to be ineffective for producing any isomerization. A grid polarizer mounted on a Teflon film was used both in irradiation and spectra recording procedures in several experiments.

The ab initio SCF MO calculations were carried out using the Gaussian 92 program package, ${ }^{13}$ running in a VAX 9000 computer, using both the $3-21 \mathrm{G}$ split valence and $6-31 \mathrm{G}^{*}$ basis sets. ${ }^{14-16}$ Molecular geometries were optimized by the force gradient method using Berny's algorithm. ${ }^{17}$ The Cartesian harmonic force constants were calculated for all the studied conformations and converted to internal coordinates using the program Transformer. ${ }^{18}$ This program was also used to prepare the input data for the normal-coordinate analysis programs used in this study (Build-G and Vibrat ${ }^{19,20}$ ). The calculated force fields were then scaled down by using a simple linear regression in order to adjust the calculated frequencies of the most stable conformer of the studied molecule to the observed frequencies. Frequencies of the less stable conformers were then calculated from the corresponding force fields by interpolation using the straight line obtained previously. While very simple, this scaling procedure has the advantage over the more elaborate force field scaling procedures which use several scale factors for preser- ving the potential-energy distributions (PEDs) as they emerge from the $a b$ initio calculations.

\section{Results and Discussion}

\section{Molecular Energies and Geometries}

Both the 3-21G and 6-31G* ab initio calculations account for four different stable conformations of the dichloroacetic acid monomer molecule (see Fig. 1 and Table 1). In consonance with previous studies, ${ }^{5-12}$ these calculations predict that the first and the second more stable forms correspond to structures having an $s$-cis $\mathrm{O}=\mathrm{C}-\mathrm{O}-\mathrm{H}$ axis [the $s y n / s$-cis (SC) and skew/s-cis (SKC) conformers]. In addition, the calculated energies of these two conformers were also found to be very close to each other. However, the 3-21G calculations point to a most stable SKC form $\left(\Delta E_{\mathrm{SKC}-\mathrm{sc}}=-1.25 \mathrm{~kJ} \mathrm{~mol}^{-1}\right)$, while the $6-31 G^{*}$ basis set predicts the SC form as the most stable conformer $\left(\Delta E_{\mathrm{SKC}-\mathrm{sc}}=3.04 \mathrm{~kJ} \mathrm{~mol}^{-1}\right)$. Our previous study on chloroacetic acid showed that, despite the fact that the 3-21G basis yields both good structural and good vibrational results for these kinds of molecule, it is not good for predicting relative conformational energies. ${ }^{2}$ Indeed, this also seems to occur in the present case, as the vibrational data obtained in this study clearly indicate that the SC conformer corresponds to the most stable form of dichloroacetic acid, as it will be stressed in the next sections.

The two high-energy conformers predicted by both basis sets correspond to the syn/s-trans (ST) and skew/s-trans (SKT) forms (see Fig. 1), being, respectively, 19-22 and ca. 30 $\mathrm{kJ} \mathrm{mol}{ }^{-1}$ less stable than the lowest energy SC form (see Table 1).

The calculated molecular geometries for the various conformers of dichloroacetic acid are shown in Table 2. While the agreement between experimental ${ }^{12}$ and calculated geometries is generally good, the following specific comments should be made: (i) As is usual, ${ }^{21}$ at the $6-31 \mathrm{G}^{*}$ level of calculation, the $\mathrm{C}-\mathrm{O}$ bond lengths are too short. On the other hand, the $\mathrm{C}-\mathrm{Cl}$ bond lengths and the $\mathrm{C}-\mathrm{C}=\mathrm{O}, \mathrm{C}-\mathrm{C}-\mathrm{O}$ and $\mathrm{C}-\mathrm{O}-\mathrm{H}$ angles show a much better agreement with experiment, thus stressing the relevance of polarization orbitals in MO calculations of geometries of $\alpha$ chlorosubstituted carbonyl compounds. Indeed, these results agree with our previous data on chloroacetic acid. ${ }^{2}$

(ii) The $6-31 \mathrm{G}^{*}$ calculated value of the $\mathrm{H}-\mathrm{C}-\mathrm{C}=\mathrm{O}$ dihedral angle for the SKC conformer (144.5 ) agrees within the experimental error with the experimental value obtained by microwave spectroscopy $\left(145.9 \pm 1.6^{\circ 12}\right)$, whereas the $3-21 \mathrm{G}$ calculated value for this angle is too low $\left(136.5^{\circ}\right)$. On the other hand, both bases predict that the $\mathrm{H}-\mathrm{C}-\mathrm{C}=\mathrm{O}$ dihedral angle of the highest energy SKT conformer is considerably smaller than this angle in the SKC form (3-21G, 109.2 $\left.6-31 \mathrm{G}^{*}, 101.3^{\circ}\right)$. Furthermore, as a lower $\mathrm{H}-\mathrm{C}-\mathrm{C}=\mathrm{O}$ angle correlates with a reduction in the $\mathrm{Cl} \cdots \mathrm{H}(\mathrm{O})$ distance involving the chlorine atom which is closer to the hydroxy group, this result seems to indicate that an attractive interaction may exist between the $\mathrm{Cl}$ and the hydroxy-group $\mathrm{H}$ atoms in

Table 1 Calculated conformational energy differences (kJ $\mathrm{mol}^{-1}$ ) for dichloroacetic acid

\begin{tabular}{lccc}
\hline & $3-21 \mathrm{G}$ & $6-31 G^{*}$ & $\mathrm{MM}(\mathrm{PF} 1)^{a}$ \\
\hline$\Delta E_{\text {SKC-SC }}$ & -1.25 & 3.04 & -0.63 \\
$\Delta E_{\mathrm{ST}-\mathrm{SC}}$ & 22.0 & 19.0 & 33.3 \\
$\Delta E_{\mathrm{SKT}-\mathrm{SC}}$ & 30.7 & 30.7 & 26.9 \\
$\Delta E_{\mathrm{SKC} \rightarrow \text { SKC }}$ & 4.25 & 1.96 & 1.70 \\
\hline
\end{tabular}

${ }^{a}$ Ref. 10. 
Table 2 Calculated (3-21G and 6-31G*) and experimental molecular geometries, relative energies and dipole moments of the relevant conformations of dichloroacetic acid ${ }^{a}$

\begin{tabular}{|c|c|c|c|c|c|c|c|c|c|}
\hline \multirow[b]{2}{*}{ parameter $^{b}$} & \multicolumn{3}{|c|}{ SKC } & \multicolumn{2}{|c|}{ SC } & \multicolumn{2}{|c|}{ ST } & \multicolumn{2}{|c|}{ SKT } \\
\hline & $3-21 G$ & 6-31G* & exp.c & $3-21 G$ & $6-31 G^{*}$ & $3-21 G$ & $6-31 \mathrm{G}^{*}$ & $3-21 G$ & $6-31 G^{*}$ \\
\hline $\mathrm{C}-\mathrm{C}$ & 150.5 & 152.6 & 150.9 & 150.1 & 152.2 & 151.6 & 153.1 & 152.5 & 154.2 \\
\hline $\mathrm{C}=\mathrm{O}$ & 119.3 & 117.8 & 120.8 & 119.8 & 118.3 & 119.3 & 117.7 & 118.9 & 117.4 \\
\hline $\mathrm{C}-\mathrm{O}$ & 134.8 & 132.3 & 134.9 & 133.7 & 131.5 & 134.0 & 131.9 & 134.7 & 132.3 \\
\hline $\mathrm{O}-\mathrm{H}$ & 96.9 & 95.3 & 97.1 & 96.9 & 95.3 & 96.6 & 95.0 & 96.5 & 94.9 \\
\hline $\mathrm{C}-\mathrm{Cl}(1)$ & 182.6 & 175.7 & 175.7 & 184.3 & 176.9 & 185.1 & 177.4 & 181.9 & 175.3 \\
\hline $\mathrm{C}-\mathrm{Cl}(2)$ & 185.5 & 177.6 & 174.7 & 184.3 & 176.9 & 185.1 & 177.4 & 186.5 & 178.5 \\
\hline $\mathrm{C}-\mathrm{H}$ & 107.0 & 107.4 & 106.2 & 106.9 & 107.3 & 106.8 & 107.2 & 107.3 & 107.8 \\
\hline $\mathrm{C}-\mathrm{C}=\mathrm{O}$ & 127.1 & 125.8 & 125.4 & 123.3 & 121.7 & 121.1 & 120.2 & 123.4 & 122.2 \\
\hline $\mathrm{O}=\mathrm{C}-\mathrm{O}$ & 124.7 & 124.8 & 123.2 & 124.9 & 125.0 & 122.7 & 122.9 & 122.2 & 122.3 \\
\hline $\mathrm{C}-\mathrm{C}-\mathrm{O}$ & 108.2 & 109.4 & 111.4 & 111.8 & 113.3 & 116.2 & 116.9 & 114.4 & 115.5 \\
\hline $\mathrm{C}-\mathrm{O}-\mathrm{H}$ & 113.0 & 108.9 & 106.1 & 113.3 & 108.9 & 117.0 & 113.4 & 117.2 & 113.8 \\
\hline $\mathrm{Cl}(1)-\mathrm{C}-\mathrm{C}$ & 111.4 & 111.7 & 111.6 & 110.0 & 110.7 & 109.8 & 110.5 & 111.7 & 112.0 \\
\hline $\mathrm{Cl}(2)-\mathrm{C}-\mathrm{C}$ & 108.1 & 108.3 & 108.7 & 110.0 & 110.7 & 109.8 & 110.5 & 109.8 & 111.8 \\
\hline $\mathrm{H}-\mathrm{C}-\mathrm{C}$ & 111.4 & 109.6 & 110.1 & 110.5 & 107.6 & 111.0 & 108.1 & 111.3 & 107.8 \\
\hline $\mathrm{C}-\mathrm{C}(=\mathrm{O}) \mathrm{O}$ & 179.9 & 180.5 & 180.0 & 180.0 & 180.0 & 180.0 & 180.0 & 176.0 & 174.6 \\
\hline $\mathrm{O}=\mathrm{C}-\mathrm{O}-\mathrm{H}$ & 3.3 & 2.5 & 0.0 & 0.0 & 0.0 & 180.0 & 180.0 & 167.7 & 172.0 \\
\hline $\mathrm{H}-\mathrm{C}-\mathrm{C}=\mathrm{O}$ & 136.5 & 144.5 & 145.9 & 0.0 & 0.0 & 0.0 & 0.0 & 109.2 & 101.3 \\
\hline $\mathrm{Cl}(1)-\mathrm{C}-\mathrm{C}=\mathrm{O}$ & 14.2 & 24.5 & 25.9 & 119.3 & 117.6 & 119.9 & 118.2 & -11.6 & -16.9 \\
\hline $\mathrm{Cl}(2)-\mathrm{C}-\mathrm{C}=\mathrm{O}$ & -107.0 & -99.2 & -97.8 & -119.3 & -117.6 & -119.9 & -118.2 & -134.3 & -142.5 \\
\hline$\Delta E^{d} / \mathrm{kJ} \mathrm{mol}^{-1}$ & -1.25 & 3.04 & - & - & - & 23.2 & 19.0 & 30.7 & 30.7 \\
\hline$|\mu| / \mathrm{D}$ & 3.06 & 2.79 & - & 1.31 & 0.94 & 2.37 & 2.61 & 3.88 & 3.66 \\
\hline
\end{tabular}

${ }^{a}$ Bond lengths in pm; angles in degrees. ${ }^{b}$ See Fig. 1 for atom numbering. ${ }^{c}$ Experimental values obtained by microwave spectroscopy; the geometric parameters given in italics were assumed. ${ }^{12}$ d Relative energies with respect to that of the SC conformer.

the SKT conformer. However, considering the high energy of this form when compared with those of all the other conformers of dichloroacetic acid (see Table 1), it can be easily concluded that this attractive interaction must be very weak. Thus, the existence of a hydrogen-bonding-type interaction, similar to that exhibited by the anti/s-trans conformer of chloroacetic acid, ${ }^{1,2}$ is not supported by the calculations.

Comparison of the calculated geometries of the various conformers leads to the following conclusions: (i) The much lower energies of the $s$-cis conformers suggest that the most important intramolecular interaction in energetic terms is the stabilizing $\mathrm{C}=\mathrm{O} \cdots \cdots \mathrm{O}-\mathrm{H}$ bond dipolar interaction (or through-space field interaction) present in these forms, where the $\mathrm{C}=\mathrm{O}$ and $\mathrm{O}-\mathrm{H}$ bonds are aligned antiparallel. The longer $\mathrm{O}-\mathrm{H}$ bond lengths in the s-cis conformers are due to this effect, which leads to an electronic charge migration from the overlap $\mathrm{O}-\mathrm{H}$ region towards the $\mathrm{O}$ atom. In addition, the longer $\mathrm{C}=\mathrm{O}$ bond lengths calculated for the s-cis conformers are also due to this interaction, which also makes this bond weaker. Interestingly, the theoretical vibrational results reinforce this interpretation: both $v(\mathrm{O}-\mathrm{H})$ and $v(\mathrm{C}=\mathrm{O})$ stretching vibrations are calculated to occur at lower frequencies in the $s$-cis conformers.

(ii) Both $\mathrm{H} \cdots \mathrm{H}(\mathrm{O})$ and $\mathrm{Cl} \cdots \mathrm{H}(\mathrm{O})$ interactions (which occur only in the s-trans forms) have important structural implications. The former seems to be responsible, at least in part, for the higher energy of the SKT form when compared with the ST conformer. In turn, the latter determines the relative values of the $\mathrm{C}-\mathrm{O}-\mathrm{H}$ angles in the s-cis and s-trans forms, leading to much larger $\mathrm{C}-\mathrm{O}-\mathrm{H}$ angles in the s-trans forms. As referred to above, however, the $\mathrm{Cl} \cdot \mathrm{H}(\mathrm{O})$ interactions do not seem to be very important in energy terms.

(iii) The most important intramolecular interactions which are distinct in the SC and SKC forms (and thus are largely responsible for the different properties exhibited by these two forms) are the $\mathrm{Cl}-\mathrm{C} \cdots \cdot \mathrm{C}=\mathrm{O}$ bond dipolar interactions and $\mathrm{Cl} \cdots \mathrm{O}$ (both $\mathrm{Cl} \cdots \mathrm{O}=$ and $\mathrm{Cl} \cdots-\mathrm{O}-$ ) steric repulsions. In structural terms, these interactions are reflected in the relative values of the $\mathrm{C}=\mathrm{O}, \mathrm{C}-\mathrm{O}$ and $\mathrm{C}-\mathrm{Cl}$ bond length as well as in the $\mathrm{Cl}-\mathrm{C}-\mathrm{C}, \mathrm{H}-\mathrm{C}-\mathrm{C}, \mathrm{C}-\mathrm{C}=\mathrm{O}$ and $\mathrm{C}-\mathrm{C}-\mathrm{O}$ angles. Considering the internal rotation about the $\mathrm{C}_{\alpha}-\mathrm{C}$ bond for a fixed $s$-cis $\mathrm{O}=\mathrm{C}-\mathrm{O}-\mathrm{H}$ axis, the calculations show that the $\mathrm{Cl}-\mathrm{C}-\mathrm{C}$ and $\mathrm{C}-\mathrm{C}=\mathrm{O}$ angles attain their maximum values for the conformations where one chlorine atom is eclipsed with the carbonyl bond, whereas the $\mathrm{C}-\mathrm{C}-\mathrm{O}$ angle attains its minima for these conformations. Interestingly, the $\mathrm{O}=\mathrm{C}-\mathrm{O}$ angles do not change very much, always being $c a .125^{\circ}$ (however, it changes to $c a .122^{\circ}$ for an s-trans $\mathrm{O}=\mathrm{C}-\mathrm{O}-\mathrm{H}$ axis; see Table 2). The $\mathrm{H}-\mathrm{C}-\mathrm{C}$ angle seems to adjust its value to those of the $\mathrm{Cl}-\mathrm{C}-\mathrm{C}$ angles, thus being smaller when the sum of the latter is larger. Hence, these changes in angles appear to be mainly determined by steric reasons. On the other hand, the relative values of the $\mathrm{C}=\mathrm{O}, \mathrm{C}-\mathrm{O}$ and $\mathrm{C}-\mathrm{Cl}$ bond lengths in the $\mathrm{SC}$ and SKC forms are essentially determined by the bond dipolar interactions (or field effect). In the SKC form, the bond dipoles associated with the nearly eclipsed $\mathrm{C}-\mathrm{Cl}$ and $\mathrm{C}=\mathrm{O}$ bonds point in the same direction. This leads to an electronic charge migration from both the eclipsed chlorine and oxygen atoms towards the $\mathrm{C}-\mathrm{Cl}_{\text {eclipsed }}$ and $\mathrm{C}=\mathrm{O}$ bonds. Hence, both these bonds become stronger and shorter. Furthermore, this interpretation is reinforced by the relative values of the $v(\mathrm{C}=\mathrm{O})$ stretching vibrational frequency in the SC and SKC forms, $v(\mathrm{C}=\mathrm{O})$ being larger in the latter conformer. Note that the results also seem to indicate that this field effect is felt to a greater extent by the $\mathrm{C}-\mathrm{Cl}$ than by the $\mathrm{C}=\mathrm{O}$ bond (see Table 2), which is in consonance with the larger polarizability of a chlorine atom than of an oxygen. Finally, the $\mathrm{C}-\mathrm{O}$ bond length attains its minimum value (i.e. the $\mathrm{C}-\mathrm{O}$ bond becomes stronger) in the $\mathrm{SC}$ conformer, where the vector sum of the two bond dipoles associated with the two $\mathrm{C}-\mathrm{Cl}$ bonds is aligned parallel with the bond dipole associated with this bond. Note, however, that in this case $v(\mathrm{C}-\mathrm{O})$ does not correlate directly with the $\mathrm{C}-\mathrm{O}$ bond length, occurring at higher frequencies in the SKC form. Indeed, this is not surprising, because this vibration is mixed to a considerable extent (mainly with the $\mathrm{C}-\mathrm{O}-\mathrm{H}$ bending vibration), as will be seen in detail in the next sections. 
Table 3 Calculated $\left(6-31 G^{*}\right)$ vibrational frequencies, infrared intensities and PEDs, and experimental frequencies for the SC conformer of dichloroacetic acid $^{a}$

\begin{tabular}{|c|c|c|c|c|c|c|c|}
\hline & & \multicolumn{3}{|r|}{$a b$ initio } & \multirow{2}{*}{$\begin{array}{c}\text { scaled } \\
\text { frequency }\end{array}$} & \multicolumn{2}{|c|}{ experimental $^{b}$} \\
\hline \multicolumn{2}{|c|}{ assignment } & frequency & $A_{\text {IR }}$ & $\operatorname{PED}(\%)^{c}$ & & frequency $^{d}$ & $A_{\mathrm{IR}}{ }^{e}$ \\
\hline$v(\mathrm{O}-\mathrm{H})$ & $\mathbf{A}^{\prime}$ & 4052 & 158 & $S_{1}[100]$ & 3562 & 3567 & 126 \\
\hline$v(\mathrm{C}-\mathrm{H})$ & $\mathbf{A}^{\prime}$ & 3397 & 2 & $S_{7}[100]$ & 2986 & $\begin{array}{l}3008^{f} \\
1798\end{array}$ & $\overline{123}$ \\
\hline$v(\mathrm{C}=\mathrm{O})$ & $A^{\prime}$ & 2054 & 424 & $S_{4}[94]$ & 1809 & $\left\{\begin{array}{l}1780 \\
1772\end{array}\right.$ & $\begin{array}{l}143 \\
177\end{array}$ \\
\hline$v(\mathrm{C}-\mathrm{O})$ & $\mathbf{A}^{\prime}$ & 1538 & 116 & $S_{5}[39]+S_{6}[22]+S_{13}[20]+S_{14}[18]$ & 1357 & $\left\{\begin{array}{l}1381 \\
1353\end{array}\right.$ & $\begin{array}{l}40 \\
36\end{array}$ \\
\hline $\begin{array}{l}\delta(\mathrm{CH})_{\text {i.p. }} \\
\delta(\mathrm{CH})_{\text {o.o.p. }}\end{array}$ & $\begin{array}{l}\mathbf{A}^{\prime} \\
\mathbf{A}^{\prime \prime}\end{array}$ & $\begin{array}{l}1416 \\
1401\end{array}$ & $\begin{array}{l}16 \\
36\end{array}$ & $\begin{array}{l}S_{12}[78]+S_{9}[25] \\
S_{1,}[60]+S_{10}[51]\end{array}$ & $\begin{array}{l}1250 \\
1238\end{array}$ & $\begin{array}{l}1251 \\
1227\end{array}$ & $\begin{array}{r}7 \\
51\end{array}$ \\
\hline$\delta(\mathrm{C}-\mathrm{O}-\mathrm{H})$ & $\mathrm{A}^{\prime}$ & 1335 & 234 & $S_{13}[64]+S_{4}[30]$ & 1180 & 1153 & 205 \\
\hline$v(\mathrm{C}-\mathrm{C})$ & $\mathbf{A}^{\prime}$ & 999 & 6 & $S_{6}[47]+S_{4}[24]+S_{3}[15]$ & 886 & 899 & 11 \\
\hline$v\left(\mathrm{CCl}_{2}\right)_{\mathrm{as}}$ & $\mathrm{A}^{\prime \prime}$ & 939 & 35 & $S_{2}[47]+S_{16}[58]+S_{10}[12]+S_{11}[11]$ & 833 & 825 & 79 \\
\hline$v\left(\mathrm{CCl}_{2}\right)_{\mathrm{s}}$ & $\mathbf{A}^{\prime}$ & 834 & 29 & $S_{3}[42]+S_{15}[21]+S_{9}[19]+S_{8}[11]$ & 741 & 766 & 22 \\
\hline$\gamma(\mathrm{C}=\mathrm{O})$ & $A^{\prime \prime}$ & 789 & 197 & $S_{16}[35]+S_{2}[59]+S_{17}[30]$ & 702 & 698 & 177 \\
\hline$\delta(\mathrm{O}=\mathrm{C}-\mathrm{O})$ & $\mathbf{A}^{\prime}$ & 670 & 99 & $S_{14}[73]+S_{9}[14]+S_{13}[14]$ & 597 & 608 & 102 \\
\hline$\tau(\mathrm{C}-\mathrm{O})$ & $A^{\prime \prime}$ & 606 & 78 & $S_{17}[72]$ & 541 & $\begin{array}{l}540 \\
535\end{array}$ & $\begin{array}{l}72 \\
60\end{array}$ \\
\hline$\delta(\mathrm{C}-\mathrm{C}=\mathrm{O})$ & $A^{\prime}$ & 461 & 2 & $S_{15}[28]+S_{3}[40]+S_{6}[13]$ & 414 & 438 & 2 \\
\hline$\delta\left(\mathrm{CCl}_{2}\right)$ & $A^{\prime}$ & 295 & 1 & $S_{8}[59]+S_{15}[22]$ & 268 & $272^{f}$ & - \\
\hline$\omega\left(\mathrm{CCl}_{2}\right)$ & $\mathbf{A}^{\prime}$ & 240 & 2 & $S_{9}[31]+S_{15}[23]+S_{8}[18]+S_{12}[16]$ & 220 & $226^{f}$ & - \\
\hline$\gamma\left(\mathrm{CCl}_{2}\right)$ & $\mathbf{A}^{\prime \prime}$ & 201 & 0 & $S_{10}[50]+S_{11}[25]+S_{16}[25]$ & 186 & $200^{f}$ & - \\
\hline$\tau(\mathrm{C}-\mathrm{C})$ & $\mathrm{A}^{\prime \prime}$ & 54 & 3 & $S_{18}[70]+S_{11}[15]$ & 57 & $17^{f}$ & - \\
\hline
\end{tabular}

${ }^{a}$ Frequencies in $\mathrm{cm}^{-1}$; intensities in $\mathrm{km} \mathrm{mol}^{-1} ; v$, stretching; $\delta$, bending; $\omega$, wagging; $\gamma$, rocking; $\tau$, torsion; i.p., in-plane; o.o.p., out-of-plane; see Table 7 for coordinates definition. ${ }^{b}$ Experimental data refer to the infrared spectrum of the monomer of dichloroacetic acid isolated in an Ar matrix; the observed frequencies for the molecule isolated in a $\mathrm{Kr}$ matrix do not differ from these more than $0.5 \%$. ${ }^{c} \mathrm{PEDs}<10 \%$ are not presented in the table. ${ }^{d}$ Values in italics were not used for the force field scaling. ${ }^{e}$ The experimental intensity values presented correspond to observed integral intensities normalized in such a way that the total intensity of the bands in the $4000-400 \mathrm{~cm}^{-1}$ region equals the corresponding calculated value. $f$ Value obtained with the PF1 molecular mechanics force field. ${ }^{10}$

In summary, the main intramolecular interactions which determine the relative stabilities of the different conformers of dichloroacetic acid are the $\mathrm{C}=\mathrm{O} \cdots \mathrm{O}-\mathrm{H}$ and $\mathrm{C}=\mathrm{O} \cdots \mathrm{C}-\mathrm{Cl}$ bond dipolar (through-space field) interactions, and the $\mathrm{H} \cdots \mathrm{H}(\mathrm{O})$ and $\mathrm{Cl} \cdot \mathrm{O}$ (both $\mathrm{O}=$ and $-\mathrm{O}-$ ) repulsive steric interactions. The lower energy of the $s$-cis forms, when compared with that of the $s$-trans forms, is mainly determined by the stabilizing $\mathrm{C}=\mathrm{O} \cdots \mathrm{O}-\mathrm{H}$ dipolar interaction, while the balance between the $\mathrm{Cl} \cdots \mathrm{O}$ repulsions and the $\mathrm{C}=\mathrm{O} \cdots \mathrm{C}-\mathrm{Cl}$ dipolar interaction determines the relative stability of the two s-cis forms, leading to a very slightly more stable SC form. The $\mathrm{H} \cdot \mathrm{H}(\mathrm{O})$ repulsion also seems to be important in determining the relative stability of the two s-trans forms.

\section{Vibrational Results}

Assignment of Vibrational Spectra

The IR spectra of $\mathrm{CHCl}_{2} \mathrm{CO}_{2} \mathrm{H}$ isolated in an Ar matrix are shown in Fig. 2 before $(a)$ and after $(b)$ irradiation by a non-

Table 4 Calculated $\left(6-31 \mathrm{G}^{*}\right)$ vibrational frequencies, infrared intensities and PEDs, and experimental frequencies for the SKC conformer of dichloroacetic acid ${ }^{a}$

\begin{tabular}{|c|c|c|c|c|c|c|}
\hline \multirow[b]{2}{*}{ assignment } & \multicolumn{3}{|r|}{$a b$ initio } & \multirow{2}{*}{$\begin{array}{l}\text { scaled } \\
\text { frequency }\end{array}$} & \multicolumn{2}{|c|}{ experimental $^{b}$} \\
\hline & frequency & $A_{\mathrm{IR}}$ & $\operatorname{PED}(\%)^{\mathrm{c}}$ & & frequency ${ }^{d}$ & $A_{\mathrm{IR}}{ }^{e}$ \\
\hline$v(\mathrm{O}-\mathrm{H})$ & 4046 & 156 & $S_{1}[100]$ & 3556 & 3559 & 128 \\
\hline$v(\mathrm{C}-\mathrm{H})$ & 3375 & 2 & $S_{7}[100]$ & 2967 & $3007^{f}$ & - \\
\hline$v(\mathrm{C}=\mathrm{O})$ & 2075 & 368 & $S_{4}[95]$ & 1828 & $\begin{array}{l}1827 \\
1797\end{array}$ & $\begin{array}{r}64 \\
224\end{array}$ \\
\hline$v(\mathrm{C}-\mathrm{O})$ & 1542 & 87 & $S_{5}[28]+S_{12}[23]+S_{6}[22]+S_{13}[14]+S_{14}[14]$ & 1362 & $\begin{array}{l}1373 \\
1323\end{array}$ & $\begin{array}{r}33 \\
9\end{array}$ \\
\hline$\delta(\mathrm{CH})_{\text {i.p. }}$ & 1412 & 3 & $S_{12}[33]+S_{13}[37]+S_{11}[11]+S_{9}[10]$ & 1247 & 1245 & 2 \\
\hline$\delta(\mathrm{CH})_{\text {o.o.p. }}$ & 1387 & 37 & $S_{11}[69]+S_{10}[42]$ & 1226 & 1218 & 12 \\
\hline$\delta(\mathrm{C}-\mathrm{O}-\mathrm{H})$ & 1294 & 294 & $S_{13}[31]+S_{4}[54]+S_{11}[17]$ & 1144 & 1115 & 289 \\
\hline$v(\mathrm{C}-\mathrm{C})$ & 1018 & 11 & $S_{6}[49]+S_{3}[16]+S_{4}[11]$ & 902 & 915 & 15 \\
\hline$v\left(\mathrm{CCl}_{2}\right)_{\text {as }}$ & 928 & 75 & $S_{2}[59]+S_{16}[34]+\vec{S}_{11}[11]$ & 823 & 823 & 155 \\
\hline$v\left(\mathrm{CCl}_{2}\right)_{\mathrm{s}}$ & 874 & 61 & $S_{3}[16]+S_{16}[34]+S_{9}[22]+S_{2}[15]+S_{15}[13]$ & 776 & 788 & 29 \\
\hline$\gamma(\mathbf{C}=\mathbf{O})$ & 751 & 152 & $S_{16}[13]+S_{3}[31]+S_{17}[28]+S_{14}[16]+S_{2}[16]$ & 668 & 669 & 103 \\
\hline$\delta(\mathrm{O}=\mathrm{C}-\mathrm{O})$ & 686 & 95 & $S_{14}[52]+S_{17}[13]$ & 611 & 614 & 84 \\
\hline$\tau(\mathrm{C}-\mathrm{O})$ & 607 & 56 & $S_{17}[54]+S_{16}[11]+S_{2}[10]$ & 542 & 534 & 86 \\
\hline$\delta(\mathrm{C}-\mathrm{C}=\mathrm{O})$ & 440 & 3 & $S_{15}[27]+S_{3}[29]+S_{14}[13]$ & 396 & $382^{f}$ & 一 \\
\hline$\delta\left(\mathrm{CCl}_{2}\right)$ & 307 & 0 & $S_{8}[51]+S_{15}[21]+S_{9}[10]$ & 279 & $282^{f}$ & - \\
\hline$\omega\left(\mathrm{CCl}_{2}\right)$ & 258 & 0 & $S_{9}[28]+S_{8}[26]+S_{15}[15]+S_{12}[15]$ & 236 & $246^{f}$ & - \\
\hline$\gamma\left(\mathrm{CCl}_{2}\right)$ & 205 & 1 & $S_{10}[36]+S_{11}[29]+S_{16}[17]$ & 190 & $203^{f}$ & 一 \\
\hline$\tau(\mathrm{C}-\mathrm{C})$ & 49 & 1 & $S_{18}[86]$ & 53 & $24^{f}$ & - \\
\hline
\end{tabular}

$a-d . f$ as for Table 3 , $^{\mathrm{e}}$ The experimental intensity values presented correspond to observed integral intensities normalized on the SC rotamer band intensities (Table 3 ) and using the band intensity ratios taken from the differential spectrum Fig. $2(b)-(a)$. 


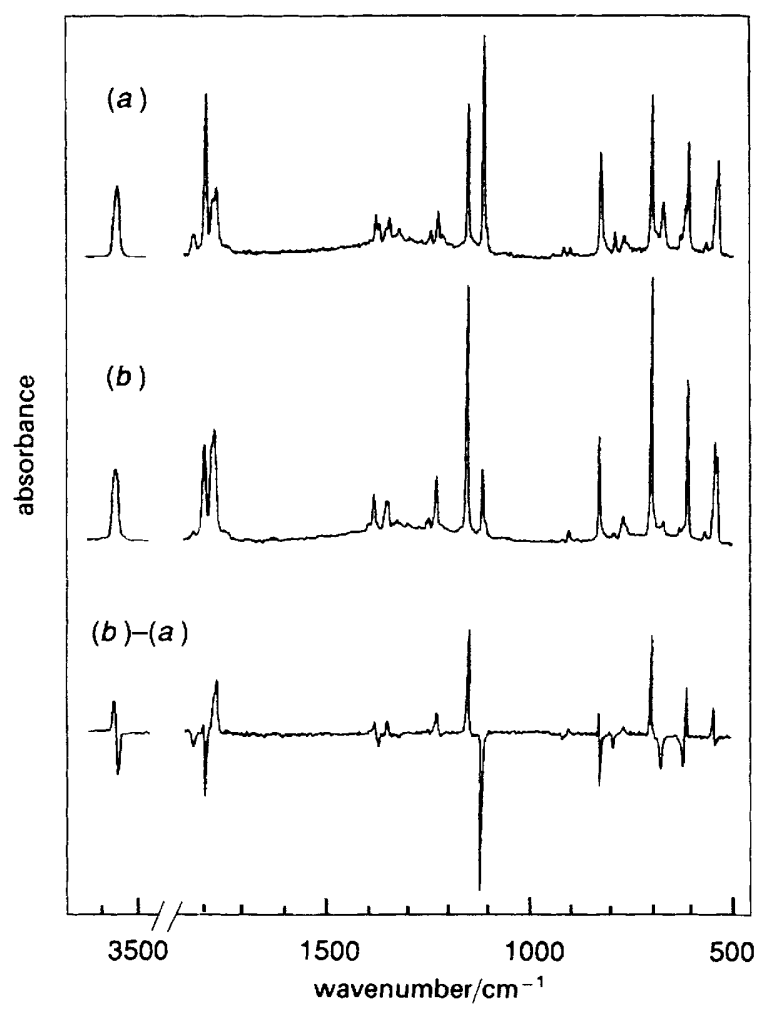

Fig. 2 IR spectra of dichloroacetic acid isolated in an argon matrix (a) after deposition at $14 \mathrm{~K},(b)$ after irradiation in the $v(\mathrm{O}-\mathrm{H})$ region

filtered spectrophotometer beam; Fig. $2(b)-(a)$ shows the difference of these two spectra.

In consonance with the energetic results of the calculations, the observed changes in the spectra upon irradiation can be due only to a rotamerization reaction between the lowest energy $s$-cis conformers. In fact, comparison with the calculated spectra unequivocally proves that irradiation promotes $\mathrm{SKC} \rightarrow \mathrm{SC}$ isomerization, and thus, the upwards bands in the difference spectrum shown in Fig. 2 originate in the SC con-

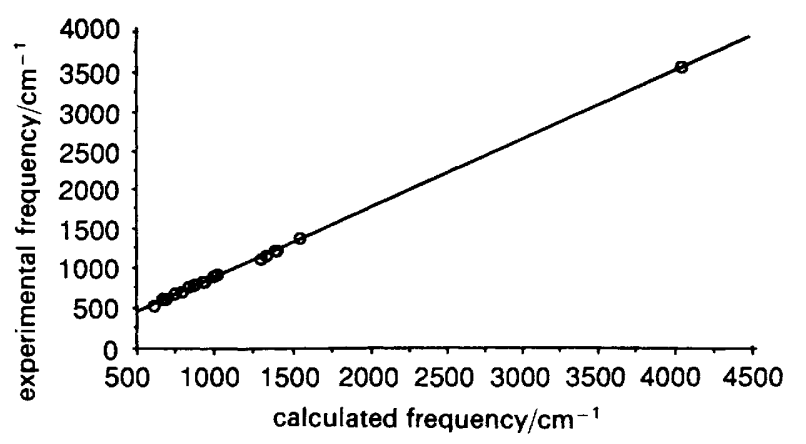

Fig. 3 Experimental (IR in Ar matrix) vs. ab initio 6-31G* calculated vibrational frequencies. Experimental frequency $=(0.876 \times$ calculated frequency) $+10.124, R^{2}=1$.

former, while the downwards bands in this spectrum are due to the SKC form.

The experimental and $6-31 \mathrm{G}^{*}$ calculated frequencies and intensities, as well as the potential-energy distribution (PED) for the SC and SKC conformers are shown in Tables 3 and 4. Tables 5 and 6 present the calculated values obtained for the higher energy s-trans forms. These tables also include the frequencies obtained with the scaled force fields. These latter show a general agreement with the experimental values to within $2-3 \%$ for the two experimentally observed conformers (see also Fig. 3).

Both the SC and the ST forms belong to the $C_{\mathrm{S}}$ point group and thus, their 18 normal modes span the irreducible representations, $12 A^{\prime}+6 A^{\prime \prime}$. In turn, the SKC and SKT forms are non-symmetric ( $C_{1}$ point group). Table 7 shows the local $C_{\mathrm{s}}$ symmetry coordinates used in the normal-coordinate analysis for all conformers.

$2800-3600 \mathrm{~cm}^{-1}$ Region. This spectral region includes the $v(\mathrm{O}-\mathrm{H})$ and $v(\mathrm{C}-\mathrm{H})$ vibrations. The bands ascribable to the $v(\mathrm{C}-\mathrm{H})$ mode could not be clearly observed experimentally either in $\mathrm{Ar}$ or $\mathrm{Kr}$ matrices, though the very weak signal appearing at $c a .2925 \mathrm{~cm}^{-1}$ is most probably due to this vibration. Indeed, in consonance with the experimental findings, the calculations predict that $v(\mathrm{C}-\mathrm{H})$ should give rise to very low intensity infrared bands in both the SC and SKC

Table 5 Calculated (6-31G*) vibrational frequencies, infrared intensities and PEDs, and experimental frequencies for the ST conformer of dichloroacetic acid $^{a}$

\begin{tabular}{|c|c|c|c|c|c|}
\hline \multirow{2}{*}{\multicolumn{2}{|c|}{ assignment }} & \multicolumn{3}{|c|}{$a b$ initio } & \multirow{2}{*}{$\begin{array}{l}\text { scaled } \\
\text { frequency }\end{array}$} \\
\hline & & \multirow{2}{*}{$\begin{array}{c}\text { frequency } \\
4083\end{array}$} & \multirow{2}{*}{$\frac{A_{\mathrm{IR}}}{115}$} & \multirow[t]{2}{*}{$\operatorname{PED}(\%)^{b}$} & \\
\hline$v(\mathrm{O}-\mathrm{H})$ & $\mathbf{A}^{\prime}$ & & & & 3587 \\
\hline$v(\mathrm{C}-\mathrm{H})$ & $\mathrm{A}^{\prime}$ & 3408 & 2 & $S_{7}[100]$ & 2996 \\
\hline$v(\mathrm{C}=\mathrm{O})$ & $\mathbf{A}^{\prime}$ & 2088 & $38 \overline{1}$ & $S_{4}[94]$ & 1839 \\
\hline$v(C-O)$ & $\mathrm{A}^{\prime}$ & 1494 & 480 & $S_{5}[51]+S_{13}[37]+S_{6}[19]+S_{14}[15]$ & 1319 \\
\hline$\delta(\mathrm{CH})_{i}$ & $\mathrm{~A}^{\prime}$ & 1402 & 21 & $S_{1,}[75]+S_{0}[24]$ & 1238 \\
\hline$\delta(\mathrm{CH})_{\text {o.o.p. }}$ & $\mathrm{A}^{\prime \prime}$ & 1392 & 37 & $S_{11}[63]+S_{10}[51]$ & 1229 \\
\hline$\delta(\mathrm{C}-\mathrm{O}-\mathrm{H})$ & $\mathbf{A}^{\prime}$ & 1328 & 12 & $S_{13}[53]+S_{4}[17]+S_{6}[15]$ & 1173 \\
\hline$v(\mathrm{C}-\mathrm{C})$ & $\mathbf{A}^{\prime}$ & 994 & 20 & $S_{6}[46]+S_{4}[27]+S_{3}[13]$ & 881 \\
\hline$v\left(\mathrm{CCl}_{2}\right)_{\text {as }}$ & $\mathrm{A}^{\prime \prime}$ & 927 & 59 & $S_{2}[45]+S_{16}[53]+S_{1}[11]+S_{10}[11]$ & 822 \\
\hline$v\left(\mathrm{CCl}_{2}\right)_{3}$ & $\mathrm{~A}^{\prime}$ & 837 & 31 & $S_{3}[43]+S_{15}[24]+S_{9}[19]+S_{8}[12]$ & 743 \\
\hline$\gamma(\mathbf{C}=\mathrm{O})$ & $\mathrm{A}^{\prime \prime}$ & 757 & 109 & $S_{16}[34]+S_{2}[69]$ & 673 \\
\hline$\delta(\mathrm{O}=\mathrm{C}-\mathrm{O})$ & $\mathbf{A}^{\prime}$ & 698 & 21 & $S_{1}[72]+S_{0}[14]$ & 622 \\
\hline$\tau(\mathbf{C}-\mathbf{O})$ & $\mathrm{A}^{\prime \prime}$ & 467 & 118 & $S_{17}[95]$ & 419 \\
\hline$\delta(\mathrm{C}-\mathrm{C}=\mathrm{O})$ & $\mathrm{A}^{\prime}$ & 461 & 5 & $S_{15}[30]+S_{5}[42]+S_{5}[14]$ & 414 \\
\hline$\delta\left(\mathrm{CCl}_{2}\right)$ & $\mathrm{A}^{\prime}$ & 299 & 9 & $S_{8}[59]+S_{15}[21]$ & 272 \\
\hline$\omega\left(\mathrm{CCl}_{2,}\right)$ & $\mathbf{A}^{\prime}$ & 246 & 9 & $S_{9}[31]+S_{8}[20]+S_{15}[17]+S_{12}[16]$ & 226 \\
\hline$\gamma\left(\mathrm{CCl}_{2}\right)$ & $\mathbf{A}^{\prime \prime}$ & 205 & 5 & $S_{10}[46]+S_{10}[28]+S_{16}[22]$ & 190 \\
\hline$\tau(\mathrm{C}-\mathrm{C})$ & $\mathbf{A}^{\prime \prime}$ & 45 & 13 & $S_{18}[73] \quad D_{110}$ & 50 \\
\hline
\end{tabular}

${ }^{a}$ As Table 3. ${ }^{b}$ PEDs $<10 \%$ are not presented. 
Table 6 Calculated (6-31G*) vibrational frequencies, infrared intensities and PEDs, and experimental frequencies for the SKT conformer of dichloroacetic acid ${ }^{a}$

\begin{tabular}{|c|c|c|c|c|}
\hline \multirow[b]{2}{*}{ assignment } & \multicolumn{3}{|r|}{$a b$ initio } & \multirow{2}{*}{$\begin{array}{c}\text { scaled } \\
\text { frequency }\end{array}$} \\
\hline & frequency & $A_{\mathrm{IR}}$ & $\operatorname{PED}(\%)^{b}$ & \\
\hline$v(\mathrm{O}-\mathrm{H})$ & 4092 & 128 & $S_{1}[100]$ & 3595 \\
\hline$v(\mathrm{C}-\mathrm{H})$ & 3334 & 4 & $S_{7}[100]$ & 2931 \\
\hline$v(\mathrm{C}=\mathrm{O})$ & 2092 & 328 & $S_{4}[96]$ & 1843 \\
\hline$v(\mathrm{C}-\mathrm{O})$ & 1495 & 366 & $S_{5}[37]+S_{13}[31]+S_{6}[18]+S_{12}[16]+S_{14}[11]$ & 1320 \\
\hline$\delta(\mathbf{C H})_{\text {i.p. }}$ & 1398 & 190 & $S_{12}[38]+S_{13}[30]+S_{11}[22]+S_{9}[14]+S_{11}[12]$ & 1235 \\
\hline$\delta(\mathrm{CH})_{\text {o.o.p. }}$ & 1381 & 16 & $S_{11}[63]+S_{10}[51]$ & 1220 \\
\hline$\delta(\mathbf{C}-\mathbf{O}-\mathbf{H}-\mathbf{H})$ & 1299 & 3 & $S_{13}[31]+S_{4}[40]$ & 1148 \\
\hline$v(\mathrm{C}-\mathrm{C})$ & 1006 & 36 & $S_{6}[51]+S_{4}[15]+S_{3}[14]$ & 891 \\
\hline$v\left(\mathrm{CCl}_{2}\right)_{\mathrm{as}}$ & 936 & 102 & $S_{2}[76]+S_{15}[20]+S_{11}[14]$ & 830 \\
\hline$v\left(\mathrm{CCl}_{2}\right)_{\mathrm{s}}$ & 880 & 9 & $S_{3}[21]+S_{16}[52]+S_{9}[21]+S_{8}[12]$ & 781 \\
\hline$\delta(\mathrm{O}=\mathrm{C}-\mathrm{O})$ & 748 & 42 & $S_{14}[63]+S_{3}[25]$ & 665 \\
\hline$\gamma(\mathrm{C}=\mathrm{O})$ & 572 & 8 & $S_{16}[20]+S_{3}[23]+S_{6}[15]+S_{17}[13]+S_{14}[11]$ & 511 \\
\hline$\tau(\mathrm{C}-\mathrm{O})$ & 482 & 143 & $S_{17}[83]$ & 432 \\
\hline$\delta(\mathrm{C}-\mathrm{C}=\mathrm{O})$ & 457 & 15 & $S_{15}[44]+S_{2}[17]+S_{6}[14]$ & 410 \\
\hline$\delta\left(\mathrm{CCl}_{2}\right)$ & 344 & 15 & $S_{8}[33]+S_{9}[24]+S_{16}[13]+S_{3}[13]$ & 311 \\
\hline$\omega\left(\mathrm{CCl}_{2}\right)$ & 282 & 3 & $S_{9}[19]+S_{8}[41]+S_{12}[11]$ & 257 \\
\hline$\gamma\left(\mathrm{CCl}_{2}\right)$ & 242 & 8 & $S_{10}[29]+S_{11}[24]+S_{15}[14]$ & 222 \\
\hline$\tau(\mathrm{C}-\mathrm{C})$ & 32 & 6 & $S_{18}[90]$ & 38 \\
\hline
\end{tabular}

${ }_{a, b}$ As Table 5.

conformers. In addition, the calculations also indicate that in the SC form the $v(\mathbf{C}-\mathrm{H})$ vibration has a higher frequency than the SKC form. The calculated (scaled) values, $2986 \mathrm{vs}$. $2967 \mathrm{~cm}^{-1}$, respectively, are slightly lower than the molecular mechanics calculated values ( 3008 and $\left.3007 \mathrm{~cm}^{-110}\right)$, though they are within the typical range of values for this mode in a $-\mathrm{CCl}_{2} \mathrm{H}$ group adjacent to a carbonyl $\left(2970-3016 \mathrm{~cm}^{-16}\right)$.

The experimental and calculated (scaled) frequencies for the $v(\mathrm{O}-\mathrm{H})$ vibration agree very well (see Tables 3,4$)$. The calculations also predict that the frequencies of these modes are larger in the $s$-trans forms than in the $s$-cis conformers. As has been mentioned in the previous section, this happens because the anti-parallel alignment of the $\mathrm{C}=\mathrm{O}$ and $\mathrm{O}-\mathrm{H}$ bond dipole mements in the $s$-cis forms polarizes the $\mathrm{O}-\mathrm{H}$ bond, thus reducing its force constant and lowering its vibrational frequency.

$850-1850 \mathrm{~cm}^{-1}$ Region. This spectral region includes the CO stretching modes $[v(\mathrm{C}=\mathrm{O})$ and $v(\mathrm{C}-\mathrm{O})]$, the $\delta(\mathrm{CH})$ bending vibrations (in-plane and out-of-plane), the $\delta(\mathrm{C}-\mathrm{O}-\mathrm{H})$ in-plane bending mode and the $v(\mathrm{C}-\mathrm{C})$ stretching.
Previous IR studies carried out on $\alpha$-chlorosubstituted carboxylic acids in dilute $\mathrm{CCl}_{4}$ solution or isolated in an argon matrix have shown that in the spectra of both acetic and trichloroacetic acids only one band can be found in the $\mathrm{v}(\mathrm{C}=\mathrm{O})$ stretching region, whereas both chloroacetic and dichloroacetic acids have a doublet in this spectral region, the frequencies of the component bands being close to those found in acetic and trichloroacetic acids. ${ }^{1,5,22,23}$ These results were explained considering the occurrence of an upwards frequency shift due to the $\mathrm{C}=\mathrm{O} \cdot \mathrm{C}-\mathrm{Cl}$ bond dipolar interaction above discussed, which is only present in trichloroacetic acid and in those rotamers of both chloroacetic and dichloroacetic acids where the chlorine and the carbonyl oxygen atoms are nearly eclipsed (see Fig. 1)..$^{4,5,11}$ Note that it was also shown previously that in the $v(C=0)$ region of the IR spectrum of chloroacetic acid, additional bands appear which are due to a Fermi resonance interaction involving the carbonyl stretching mode. ${ }^{1}$

The IR spectra of the matrix-isolated dichloroacetic acid also show a complicated structure in the $v(\mathrm{C}=\mathrm{O})$ region. This structure is particularly evident in the spectrum of

Table 7 Definition of local $C_{\mathrm{S}}$ symmetry coordinates ${ }^{a}$

\begin{tabular}{llll}
\hline coordinate & & sym. & \multicolumn{1}{c}{ composition $^{b}$} \\
\hline$S_{1}$ & $v(\mathrm{O}-\mathrm{H})$ & $\mathrm{A}^{\prime}$ & $\Delta(\mathrm{O}-\mathrm{H})$ \\
$S_{2}$ & $v\left(\mathrm{CCl}_{2}\right)_{\text {as }}$ & $\mathrm{A}^{\prime \prime}$ & $\Delta[\mathrm{C}-\mathrm{Cl}(1)]-\Delta[\mathrm{C}-\mathrm{Cl}(2)]$ \\
$S_{3}$ & $v(\mathrm{CCl})_{s}$ & $\mathrm{~A}^{\prime}$ & $\Delta[\mathrm{C}-\mathrm{Cl}(1)]+\Delta[\mathrm{C}-\mathrm{Cl}(2)]$ \\
$S_{4}$ & $v(\mathrm{C}=\mathrm{O})$ & $\mathrm{A}^{\prime}$ & $\Delta(\mathrm{C}=\mathrm{O})$ \\
$S_{5}$ & $v(\mathrm{C}-\mathrm{O})$ & $\mathrm{A}^{\prime}$ & $\Delta(\mathrm{C}-\mathrm{O})$ \\
$S_{6}$ & $v(\mathrm{C}-\mathrm{C})$ & $\mathrm{A}^{\prime}$ & $\Delta(\mathrm{C}-\mathrm{C})$ \\
$S_{7}$ & $v(\mathrm{C}-\mathrm{H})$ & $\mathrm{A}^{\prime}$ & $\Delta(\mathrm{C}-\mathrm{H})$ \\
$S_{8}$ & $\left.\delta(\mathrm{CCl})_{2}\right)$ & $\mathrm{A}^{\prime}$ & $5 \Delta(\mathrm{ClCCl})-\Delta[\mathrm{HCCl}(1)]-\Delta[\mathrm{HCCl}(2)]-\Delta[\mathrm{Cl}(1) \mathrm{CC}]-\Delta[\mathrm{Cl}(2) \mathrm{CC}]-\Delta(\mathrm{HCC})$ \\
$S_{9}$ & $\omega(\mathrm{CCl})$ & $\mathrm{A}^{\prime}$ & $\Delta[\mathrm{HCCl}(1)]+\Delta[\mathrm{HCCl}(2)]-\Delta[\mathrm{Cl}(1) \mathrm{CC}]-\Delta[\mathrm{Cl}(2) \mathrm{CC}]$ \\
$S_{10}$ & $\gamma\left(\mathrm{CCl}{ }_{2}\right)$ & $\mathrm{A}^{\prime \prime}$ & $\Delta[\mathrm{HCCl}(1)]-\Delta[\mathrm{HCCl}(2)]-\Delta[\mathrm{Cl}(1) \mathrm{CC}]+\Delta[\mathrm{Cl}(2) \mathrm{CC}]$ \\
$S_{11}$ & $\delta(\mathrm{CH})_{\text {o.o.p. }}$ & $\mathrm{A}^{\prime \prime}$ & $\Delta[\mathrm{HCCl}(1)]-\Delta[\mathrm{HCCl}(2)]+\Delta[\mathrm{Cl}(1) \mathrm{CC}]-\Delta[\mathrm{Cl}(2) \mathrm{CC}]$ \\
$S_{12}$ & $\delta(\mathrm{CH})_{\text {i.p. }}$ & $\mathrm{A}^{\prime}$ & $4 \Delta(\mathrm{CCH}-\Delta[\mathrm{HCCl}(1)]-\Delta[\mathrm{HCCl}(2)]-\Delta[\mathrm{Cl}(1) \mathrm{CC}]-\Delta[\mathrm{Cl}(2) \mathrm{CC}]$ \\
$S_{13}$ & $\delta(\mathrm{C}-\mathrm{O}-\mathrm{H})$ & $\mathrm{A}^{\prime}$ & $\Delta(\mathrm{COH})$ \\
$S_{14}$ & $\delta(\mathrm{O}=\mathrm{C}-\mathrm{O})$ & $\mathrm{A}^{\prime}$ & $2 \Delta(\mathrm{OCO})-\Delta(\mathrm{CC}-\mathrm{O})-\Delta(\mathrm{CCO})$ \\
$S_{15}$ & $\delta(\mathrm{C}-\mathrm{C}=\mathrm{O})$ & $\mathrm{A}^{\prime}$ & $\Delta(\mathrm{CC}=\mathrm{O})-\Delta(\mathrm{CCO})$ \\
$S_{16}$ & $\gamma(\mathrm{C}=\mathrm{O})$ & $\mathrm{A}^{\prime \prime}$ & $\Delta(\mathrm{C}=\mathrm{O})$ out of the C-C$-\mathrm{O}$ plane \\
$S_{17}$ & $\tau(\mathrm{C}-\mathrm{O})$ & $\mathrm{A}^{\prime \prime}$ & $\Delta(\mathrm{O}=\mathrm{C}-\mathrm{O}-\mathrm{H})$ \\
$S_{18}$ & $\tau(\mathrm{C}-\mathrm{C})$ & $\mathrm{A}^{\prime \prime}$ & $\Delta(\mathrm{H}-\mathrm{C}-\mathrm{C}=\mathrm{O})$ \\
\hline
\end{tabular}

a See Fig. 1 for atom numbering and Table 3 for other definitions. ${ }^{b}$ Normalizing factors are not presented in the table. 
dichloroacetic acid isolated in a $\mathrm{Kr}$ matrix (Fig. 4). It is clear that each one of the two conformers, SC and SKC, gives rise to at least two bands in this region and both of them contribute to the most intense band observed at $1798 \mathrm{~cm}^{-1}$. This result is particularly important, as it indicates that using this spectral region to determine the relative population of the two conformers (and, consequently their relative energy), as was done in previous infrared solution studies, ${ }^{4,5}$ may lead to wrong results.

As referred to in the previous section, the calculations predict that both $\mathrm{C}=\mathrm{O} \cdots \mathrm{O}-\mathrm{H}$ (in the $s$-cis forms, $\mathrm{SC}$ and $\mathrm{SKC}$ ) and $\mathrm{C}=\mathrm{O} \cdots \mathrm{C}-\mathrm{Cl}$ (in the skew conformers, SKC and SKT) field interactions are reflected in the relative frequencies of the $v(C=0)$ vibration in the various conformers of dichloroacetic acid. In particular, the $\mathrm{C}=\mathrm{O} \cdots \mathrm{C}-\mathrm{Cl}$ interaction makes the SKC form absorb at a higher frequency (see Tables 3 and 4). Experimental spectra show that this mode is definitely in Fermi resonance, most probably with the first overtone of the $v(\mathrm{C}-\mathrm{C})$ stretching vibration $[v(\mathrm{C}-\mathrm{C})$ occurs near $900 \mathrm{~cm}^{-1}$ ] and/or with a combination mode involving the $\delta(\mathrm{C}-\mathrm{O}-\mathrm{H})\left(c a .1150 \mathrm{~cm}^{-1}\right)$ and $\delta(\mathrm{O}=\mathrm{C}-\mathrm{O})(c a .610$ $\mathrm{cm}^{-1}$ ) bending modes. However, the centres of gravity of the bands observed in this region ascribable to both the $\mathrm{SC}$ and SKC isomers (1782 and $1804 \mathrm{~cm}^{-1}$, respectively) appear close to the frequencies ascribed to the $v(\mathrm{C}=\mathrm{O})$ fundamental in chloroacetic acid $\left(1775\right.$ and $\left.1806 \mathrm{~cm}^{-1}{ }^{1}\right)$. Note that the participation of the $v(\mathrm{C}=\mathrm{O})$ fundamental in Fermi resonance is also supported by the fact that the calculated intensities for this mode in both the SC and SKC conformers are in better agreement with the total intensities resulting from adding the individual contributions of all the bands observed in this spectral region that are due to a given conformer (see Tables 3 and 4$)$

The $v(\mathrm{C}-\mathrm{O})$ stretching mode also seems to be involved in a Fermi resonance interaction (at least in the SC conformer).

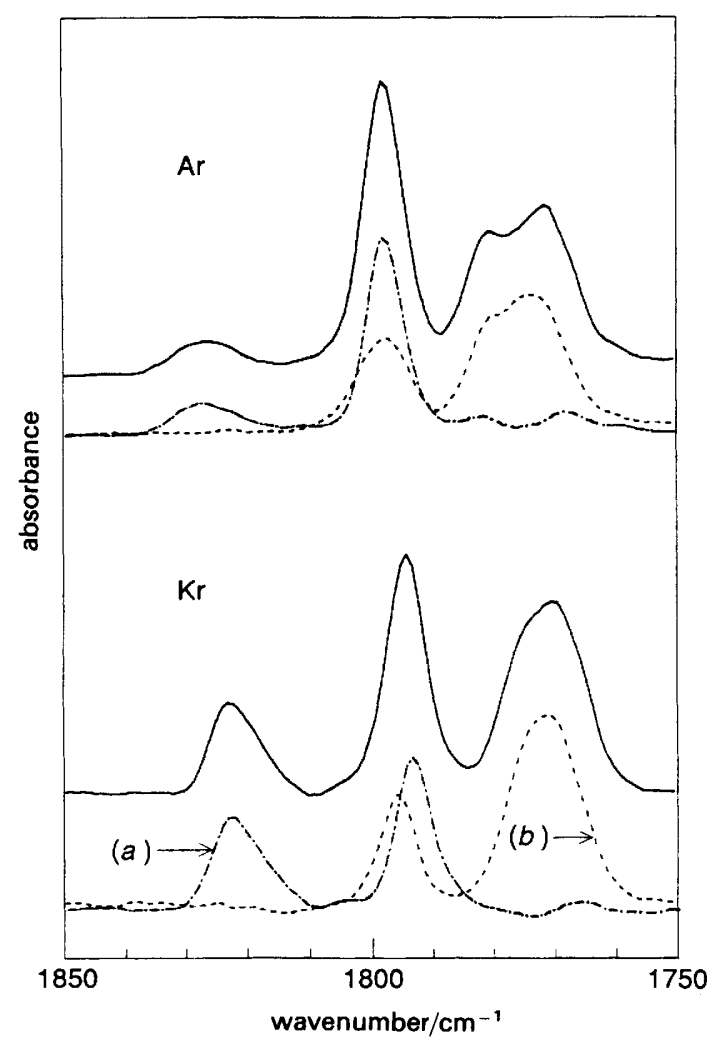

Fig. 4 Results of spectra separation [ $v(\mathrm{C}=\mathrm{O})$ region]. (a) SKC conformer, (b) SC conformer.
In fact, the spectrum of the SC form shows a doublet in this region (at 1381 and $1353 \mathrm{~cm}^{-1}$ ), the two bands having nearly identical intensity. The intensity of a single component is much lower than the predicted value, thus in consonance with the participation of the $v(\mathrm{C}-\mathrm{O})$ mode in a Fermi resonance interaction. In this case, the best candidate is the first overtone of the $\gamma(C=0)$ rocking mode, which occurs at 698 $\mathrm{cm}^{-1}$. The calculations predict that in the SKC conformer, the $v(\mathrm{C}-\mathrm{O})$ vibration should occur at a higher frequency than in the SC form. Thus, we assigned the $v(\mathrm{C}-\mathrm{O})$ fundamental vibration in the SKC form to the $1773 \mathrm{~cm}^{-1}$ band. It is also possible that the $v(\mathrm{C}-\mathrm{O})$ vibration in the SKC conformer participates in a Fermi resonance interaction. However, considering its higher frequency $\left(1373 \mathrm{~cm}^{-1}\right)$ and the lower frequency of the $\gamma(C=0)$ fundamental $\left(669 \mathrm{~cm}^{-1}\right)$, when compared with the corresponding frequencies of the SC conformer, this interaction must be much weaker than that observed in this latter conformer. Indeed, the band at 1323 $\mathrm{cm}^{-1}$, which is the only candidate to be the second component of the possible Fermi doublet involving the $v(\mathrm{C}-\mathrm{O})$ mode in the SKC form, is very weak (see Fig. 2).

Note that the $v(\mathrm{C}-\mathrm{O})$ vibration is mixed to a considerable extent, mainly with the $v(\mathrm{C}-\mathrm{C})$ stretching and $\delta(\mathrm{C}-\mathrm{O}-\mathrm{H})$ bending vibrations. This feature was also previously found in chloroacetic acid. ${ }^{2}$

The assignment of the $\delta(\mathrm{C}-\mathrm{H})$ (in-plane and out-of-plane) and $\delta(\mathrm{C}-\mathrm{O}-\mathrm{H})$ bending and $v(\mathrm{C}-\mathrm{C})$ stretching modes is straighforward. The most interesting result is the fact that the calculations were able to predict quite well both the frequencies and the relative intensities associated with these vibrations in the experimentally observed conformers (see Table 3 and 4).

$400-850 \mathrm{~cm}^{-1}$ Region. In this spectral region appear the bands due to the $v\left(\mathrm{CCl}_{2}\right)$ stretching (symmetric and antisymmetic) vibrations, the $\gamma(\mathrm{C}=\mathrm{O})$ and $\delta(\mathrm{O}=\mathrm{C}-\mathrm{O})$ bending modes, the $\tau(\mathrm{C}-\mathrm{O})$ torsions and the $\delta(\mathrm{C}-\mathrm{C}=\mathrm{O})$ bending of the $\mathrm{SC}$ form. The results of the theoretical calculations and the experimental data agree quite well as regards the frequencies and relative intensities of the bands ascribable to these vibrations in the experimentally observed conformers (see Tables 3 and 4). In addition, they lead previous assignments to be reviewed. . $^{5,10}$ The assignment of the $\gamma(\mathrm{C}=\mathrm{O})$ mode to the bands at 698 and $669 \mathrm{~cm}^{-1}$ in the IR spectrum of dichloroacetic acid in an Ar matrix is particularly clear, owing to its predicted high intensity (see Fig. 2 and Tables 3 and 4).

Region below $400 \mathrm{~cm}^{-1}$. This spectral region was not covered by our IR studies. In addition, there are no experimental data previously reported on this region. However, our previous molecular mechanics study considered this part of the IR spectrum of dichloroacetic acid. ${ }^{10}$ It is very interesting that the present calculations agree very well with the molecular mechanics results, with a few exceptions (see Tables 3 and 4). The largest differences between the results now obtained and those obtained by molecular mechanics ${ }^{10}$ occur in the $\tau(\mathrm{C}-\mathrm{C})$ frequencies (which are calculated too low by molecular mechanics), and in the $\delta(\mathrm{C}-\mathrm{C}=\mathrm{O})$ frequency of the SKC conformer. However, note that the frequency now obtained for the $\delta(\mathrm{C}-\mathrm{C}=\mathrm{O})$ mode in the SKC conformer is very close to that previously reported for methyl dichloroacetate (396 $\mathrm{cm}^{-1}$ for dichloroacetic acid vs. $395 \mathrm{~cm}^{-1}$ for methyl dichloroacetate $\left.{ }^{10}\right)$. In turn, the values now obtained for the frequencies of the torsional vibration are of the same order of magnitude as those found for the same mode in chloroacetic acid. ${ }^{24}$

Observed Bands tentatively assigned to the High-energy $S T$ Conformer. Besides the bands ascribed to the s-cis forms, there are in the spectra a number of low-intensity bands 
which remain constant during both irradiation and annealing. It is then possible that these bands originate in a third conformer present in the matrices. These bands occur at $1347,1245,628$ and $563 \mathrm{~cm}^{-1}$ and, with a single exception $\left(563 \mathrm{~cm}^{-1}\right)$, agree fairly well with calculated frequencies for both the ST or SKT conformers (see Tables 5 and 6). Considering that the $a b$ initio calculations predict the ST conformer as the third most stable one (see Table 1), these low-intensity bands can be tentatively ascribed to this conformer. However, the calculations also show that this form should give rise to a significantly intense band in the $400-450$ $\mathrm{cm}^{-1}$ region, and no such band could indeed be observed. Thus, the above mentioned low-intensity bands may also be due to some impurity present in the dichloroacetic acid used.

Note that an s-trans conformer was found for chloroacetic acid isolated in an argon matrix. ${ }^{1}$ However, in that case, the relative population of the $s$-trans conformer present in the equilibrium (the anti/s-trans form, possessing a stabilizing $\mathrm{OH} \cdot \mathrm{Cl}$ intramolecular hydrogen bond) corresponds to $\mathrm{ca}$. $15 \%,{ }^{1}$ while in dichloroacetic acid the s-trans conformers are predicted to have a population much smaller.

\section{Irradiation}

As it was mentioned before, irradiating the sample at $v(\mathrm{OH})$ causes $\mathrm{SKC} \rightarrow \mathrm{SC}$ rotamerization. The use of appropriate filters and a preliminary monochromator proves that the $v(\mathrm{O}-\mathrm{H})$ absorption is responsible for the observed photoprocess. Fig. 5 shows the ratio of the most intense IR bands assigned to the SC $\left(1153 \mathrm{~cm}^{-1}\right)$ and SKC $\left(1115 \mathrm{~cm}^{-1}\right)$ conformers of dichloroacetic acid isolated in an Ar matrix $v s$. time of irradiation. The rate of the rotamerization reaction was found to be close to first order with respect to the intensity of the light used to irradiate the sample. The differences found between the experiments carried out with the sample isolated in $\mathrm{Ar}$ or $\mathrm{Kr}$ matrices are within the limits of the experimental error.

It can be observed that the SKC form does not disappear completely upon irradiation. In fact, $A_{1115} / A_{1153} \rightarrow c a .0 .17$ (the SKC : SC concentration ratio tends to $0.12: 1$ ), independent of the irradiation power. This result may be explained considering that the unreactive SKC conformer differs from the reactive one due to a site effect (the residual $1115 \mathrm{~cm}^{-1}$ band seems to have a slightly lower frequency than the original band), thus being insensitive to irradiation. On the other hand, the residual SKC population may also be due to the simultaneous occurrence of the reverse photoeaction process $(\mathrm{SC} \rightarrow \mathrm{SKC}$ ). In this case, 0.12 corresponds to the ratio of the reverse and direct photoreaction rates ('dark' reactions were not observed). However, the variation of the observed

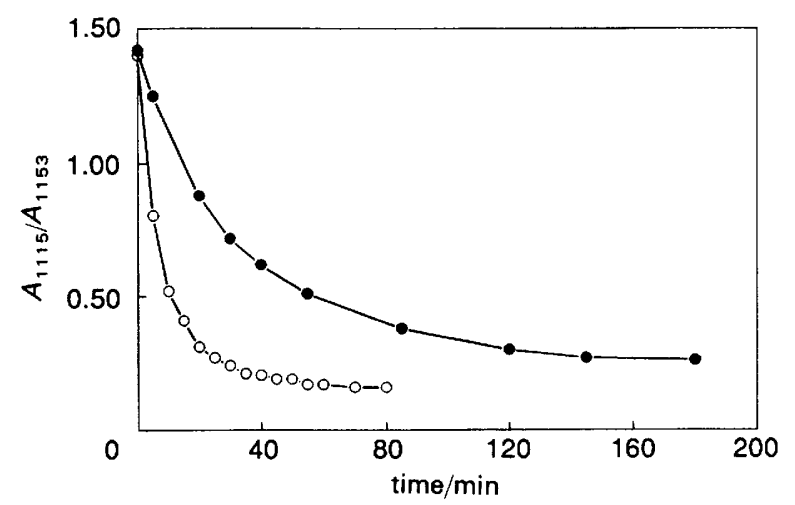

Fig. 5 Dependence of the ratio of the intensity of the IR bands at 1115 (SKC) and $1153(\mathrm{SC}) \mathrm{cm}^{-1}, A_{115} / A_{1153}$ on time of irradiation. (O), Irradiation using the spectrophotometer beam; (O), irradiation using the monochromator (see the Experimental).
$\left[A_{115}(t)-A_{1115}(\infty)\right] /\left[A_{1153}(t)-A_{1153}(\infty)\right]$ ratio with the time of irradiation (which was found to be different from a single-exponential) favours the explanation based on a site effect. Unfortunately, we did not manage to irradiate selectively each conformer because of the very close positions of their $v(\mathrm{O}-\mathrm{H})$ bands.

We have also tried to obtain optically oriented samples through irradiation with polarized light. However, the spectral changes observed using both polarizations were found to be the same within the limits of experimental error. Note that in a previous study carried out on 2-fluoroethanol isolated in an Ar matrix, ${ }^{25}$ optical orientation of the sample was not observed, when polarized radiation in the $v(\mathrm{O}-\mathrm{H})$ region was used, although sample orientation was obtained upon irradiation in the $v(\mathrm{C}-\mathrm{H})$ region. These result were interpreted as being evidence that $v(\mathrm{O}-\mathrm{H})$ energy migrates between molecules, ${ }^{25}$ but we favour a different interpretation: the orientation of the sample is not obtained when polarized radiation in the $v(\mathrm{O}-\mathrm{H})$ region was used because the large amplitude of vibration associated with the $\tau(\mathrm{O}-\mathrm{H})$ torsional mode leads to a large uncertainty in the angle between the plane of polarization of the incident light and the transition moment of the $v(\mathrm{O}-\mathrm{H})$ vibration.

\section{Annealing}

In the $14 \mathrm{~K}$ non-annealed deposited matrices, the ratio of the SKC: SC concentrations was found to be about $49: 51$ in both $\mathrm{Ar}$ or $\mathrm{Kr}$ matrices. This ratio must be equal to the SKC : SC ratio in the jet used to prepare the samples and, thus, it can be concluded that in the gaseous phase the SC conformer is more stable than the SKC by ca. $2 \mathrm{~kJ} \mathrm{~mol}^{-1}$, if only the SKC form double degeneration is taken into account. After annealing, the SKC : SC concentration ratio becomes equal to about $33: 67$ in the Ar matrix, and $c a$. $45: 55$ in the $\mathrm{Kr}$ matrix, thus showing that the energy of the two conformers is almost the same under these conditions $\left(\Delta E_{\mathrm{SKC}-\mathrm{sc}} \approx 0.2 \mathrm{~kJ} \mathrm{~mol}^{-1}\right)$. The observed shift in the equilibrium towards the SKC form in the $\mathrm{Kr}$ matrix is in consonance with both the higher dipole moment of this conformer (the 6-31G* calculated dipole moments are: SKC, $2.79 \mathrm{D}$; $\mathrm{SC}, 0.94 \mathrm{D} \dagger$ ) and the higher polarizability of the solid krypton.

Note that the rotamerization reactions occur at different temperatures in the irradiated and non-irradiated samples. Heating of the non-irradiated samples (using an increment in temperature of $0.5 \mathrm{~K} \mathrm{~min}{ }^{-1}$ ), leads to a sharp redistribution of the IR band intensities which begins near $26 \mathrm{~K}$ and at $c a$. $24 \mathrm{~K}$ for the experiments carried out in the $\mathrm{Ar}$ and $\mathrm{Kr}$ matrices, respectively; the corresponding equilibria are reached by annealing at these two temperatures. In turn, in the irradiated samples the rotamerization reactions occur at a temperature 3-4 $\mathrm{K}$ lower than in the non-irradiated samples (i.e. near $23 \mathrm{~K}$ for the Ar matrix and at ca. $20 \mathrm{~K}$ for the $\mathrm{Kr}$ matrix studies). Annealing at these temperatures always leads to an increase in the SKC concentration, even if its equilibrium concentration has been already exceeded (Fig. 6). Only after further heating, the SKC: SC population ratio becomes equal to its equilibrium value. This is observed in the data shown in curve 2 of Fig. 6, where the sample was first irradiated during a period of time long enough to allow the SKC : SC population ratio to reach its equilibrium value, and then heated: annealing of this sample leads first to an increase in the SKC concentration and only after further increases in temperature the SKC:SC population ratio returns to its equilibrium values.

$+1 \mathrm{D} \approx 3.33564 \times 10^{-30} \mathrm{Cm}$. 


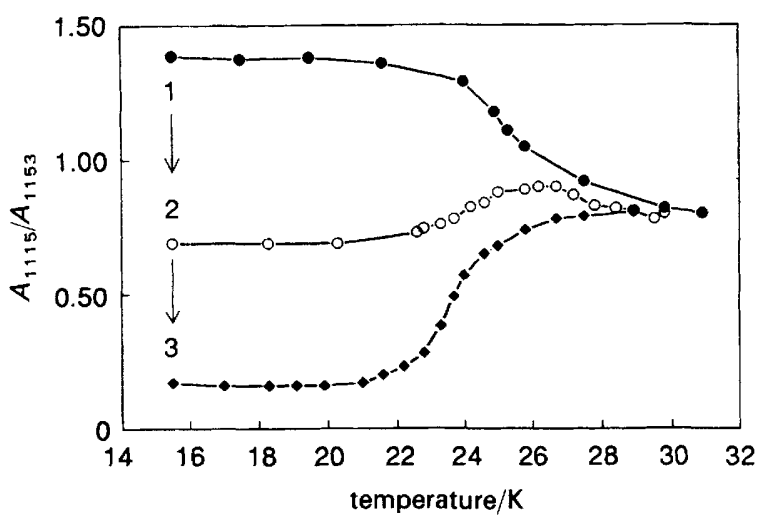

Fig. 6 Dependence of the ratio of the intensity of the IR bands at 1115 (SKC) and 1153 (SC) $\mathrm{cm}^{-1}, A_{1115} / A_{1153}$ on temperature (annealing). 1, non-irradiated sample; 2. Sample irradiated for $30 \mathrm{~min}$ by the spectrophotometer beam; 3 , sample irradiated for $1 \mathrm{~h}$ by monochromator.

It is natural to explain this effect by considering that the SC molecules formed from the SKC by photoisomerization are obtained in a non-equilibrium state with their surroundings. Let us represent these molecules as $\mathrm{SC}^{*}$. Obviously, the $\mathrm{SC}^{*}$ molecules should be less stable than the SC and, thus, the energy barrier for the reverse reaction should be lower than that of the normal reverse reaction involving the SC molecules in equilibrium with their surroundings.

It can be estimated, using Barns' correlation, ${ }^{26}$ that a $4 \mathrm{~K}$ decrease in the temperature of rotamerization corresponds to a decrease in the energy barrier of $1-2 \mathrm{~kJ} \mathrm{~mol}^{-1}$. Thus, $\Delta E_{\mathrm{SC}^{*}-\mathrm{SKc}}$ must be at least $1-2 \mathrm{~kJ} \mathrm{~mol}^{-1}\left(\Delta E_{\mathrm{SC}-\mathrm{SKc}} \approx-0.2 \mathrm{~kJ}\right.$ $\mathrm{mol}^{-1}$ as mentioned before). Then, in the Ar matrix experiment, all SC* molecules should convert again to the SKC conformation at $23 \mathrm{~K}$. However, at this temperature, the experimental results show that only about $2 / 3$ of the $\mathrm{SC}^{*}$ molecules convert back to SKC. The following sequence of processes, which illustrate schematically the results shown in curve 2 of Fig. 6, explain the experimental findings :



In the first step, the SKC conformer is converted partially to the $\mathrm{SC}^{*}$ form, by irradiating the sample. In the second step (annealing at $23 \mathrm{~K}$ ), some of the $\mathrm{SC}^{*}$ molecules previously formed convert back to an SKC* conformation. The $\mathrm{SKC}^{*}$ : $\mathrm{SC}^{*}$ ratio is determined by the relative energies of the $\mathrm{SC}^{*}$ and $\mathrm{SKC}^{*}$ molecules. As referred to above, at $23 \mathrm{~K} \mathrm{ca}$ $2 / 3$ of the $\mathrm{SC}^{*}$ molecules convert to the SKC* form, meaning that the $\mathrm{SKC}^{*}: \mathrm{SC}^{*}$ population ratio is approximately equal to the SKC : SC equilibrium ratio. Thus, $\Delta E_{\mathrm{SKC}^{*}-\mathrm{SC}^{*}}$ must be equal or very close to $\Delta E_{\mathrm{SKC}-\mathrm{sc}}$, i.e. ca. $0.2 \mathrm{~kJ} \mathrm{~mol}^{-1}$. Indeed, the energy barrier for interconversion between these nonequilibrium forms is lower than that associated with the equilibrium species, as referred to above. In the third step (annealing at $26 \mathrm{~K}$ ), total equilibrium between all molecules is attained.

There are two possible explanations that account for the above mentioned decrease in the energy barrier for interconversion of the non-equilibrium species despite the fact that
$\Delta E_{\mathrm{SKC}-\mathrm{Sc}}$ stays very close to $\Delta E_{\mathrm{SKC}-\mathrm{Sc}}$. On one hand, it is possible that the molecules 'push apart' neighbouring Ar atoms in the course of the photorotamerization reaction, thus leading to a smaller energy barrier for the backwards reaction, although the relative energies of the rotamers do not change. Indeed, the calculations show that $\Delta E_{\mathrm{SKC} \rightarrow \mathrm{sc}}$ should be below $2 \mathrm{~kJ} \mathrm{~mol}^{-1}$, but according to Barns' correlation, ${ }^{26}$ the observed temperature of the thermally induced interconversion corresponds to an energy barrier of about $6 \mathrm{~kJ}$ $\mathrm{mol}^{-1}$. On the other hand, it is also possible that, instead of leading to changes in the cage, the rotamerization could occur only from a particular site position where the energy barrier is smaller. In this case a change of site position should be the first stage of rotamerization for some molecules. The non-single-exponential kinetics of photorotamerization can also be explained in the same way.

Of course, these pictures are only simple approximations, since it is not likely that only two values are possible for the height of the energy barrier in a non-annealed matrix. Indeed, some kind of distribution of values must exist. Although, the experimental results clearly show that a redistribution of the band intensities occurs at two different temperatures in irradiated samples (this is not clearly seen in Fig. 6, where the temperature increase was sufficiently slow for spectra recording, but is obvious in the course of a sufficiently rapid temperature increase). Note that a similar effect was also observed for chloroacetic acid isolated in an Ar matrix, where interconversion of rotamers in irradiated samples proceeds from 20 to $24 \mathrm{~K}^{1}$

Financial support from the Russian Foundation of Fundamental Research (grant 93-03-5664) (A.K.) and the Junta Nacional de Investigação Científica e Tecnológica (J.N.I.C.T.), Portugal (R.F.) is gratefully acknowledged. R.F. thanks the Centro do Informática da Universidade de Coimbra (CIUC) for providing computational facilities.

\section{References}

1 A. Kulbida and A. Nosov, J. Mol. Struct., 1992, 265, 17.

2 R. Fausto, F. P. S. C. Gil and J. J. C. Teixeira-Dias, J. Chem. Soc. Faraday Trans., 1993, 89, 3235.

3 R. Fausto and J. J. C. Teixeira-Dias, J. Mol. Struct., 1986, 144, 225 .

4 I. M. Ginzburg and B. P. Tarasov, Zh. Obshch. Khim., 1972, 42, 2740.

5 L. M. Babkow, V. V. Vashchinskaya, M. A. Kovner, G. A. Puchkovskaya and Yu. Ya. Fialkov, Spectrochim. Acta, Part A, 1976, 32, 1379.

6 J. E. Katon, T. H. Stout and G. G. Hess, Appl. Spectrosc., 1986, 40, 1 .

7 M. P. Jorge and J. R. Barceló, Anal. Fis. Quim. A, 1957, 53, 339.

8 R. J. Jakobsen and J. E. Katon, Spectrochim. Acta, Part A, 1973, 29, 1953.

9 K. E. Edgekombe and R. J. Boyd, Can. J. Chem., 1984, 62, 2881.

10 R. Fausto and J. J. C. Teixeira-Dias, J. Mol. Struct., 1986, 144, 241.

11 L. Bellamy, Novye Dannye po IK Spectram Slozhnykh Molecul, Mir, 1971.

12 E. van Zoeren and B. P. van Eijck, J. Mol. Struct., 1983, 97, 315.

13 M. J. Frisch, G. W. Trucks, M. Head-Gordon, P. M. W. Gill, M. W. Wong, J. B. Foresman, B. J. Johnson, H. B. Schlegel, M. A. Robb, E. S. Replogle, R. Gomperts, J. L. Andres, K. Raghavachari, J. S. Binkley, C. Gonzalez, R. L. Martin, D. J. Fox, D. J. Defrees, J. Baker, J. J. P. Stewart and J. A. Pople, Program Gaussian 92 (Revision C), Gaussian Inc., Pittsburgh PA, 1992.

14 J. S. Binkley, J. A. Pople and W. J. Hehre, J. Am. Chem. Soc., $1980,102,939$.

15 M. S. Gordon, J. S. Binkley, J. A. Pople, W. J. Pietro and W. J. Hehre, J. Am. Chem. Soc., 1982, 104, 2797.

16 W. J. Hehre, R. Ditchfield and J. A. Pople, J. Am. Chem. Soc., 1972, 56, 2257.

17 H. B. Schlegel, Ph.D. Thesis, Queen's University, Kingston, 1975. 
18 M. D. G. Faria and R. Fausto, Program Transformer, Department of Chemistry, University of Coimbra, 1990.

19 M. D. G. Faria and R. Fausto, Program Build-G, Department of Chemistry, University of Coimbra, 1990, This program incorporates several routines from Program GMAT, by $H$. Fuher, K. B. Kartha, K. G. Kidd, P. J. Krueger and H. H. Mantsch, Natl. Res. Counc. Can. Bull., 1976, no. 15.

20 M. D. G. Faria and R. Fausto, Program Vibrat, Department of Chemistry, University of Coimbra, 1990, This program incorporates several routines from Program FPERT, by $\mathbf{H}$. Fuher, $\mathrm{K}$ B. Kartha, K. G. Kidd, P. J. Krueger and H. H. Mantsch, Natl. Res. Counc. Can. Bull., 1976, no. 15.

21 P. Pulay, in Recent Experimental and Computational Advances in Molecular Spectroscopy, ed. R. Fausto, NATO-ASI Series C, vol. 406, Kluwer, Dordrecht, 1993.
22 V. Berney, R. L. Redington and K. C. Lin, J. Chem. Phys., 1970, 53,1713 .

23 R. L. Redington and K. C. Lin, Spectrochim. Acta, Part A, 1971, 27,2445 .

24 B. P. van Eijck, A. A. J. Maagdenberg and J. Wanrooy, J. Mol. Struct., 1974, 22, 6.

25 W. H. Hoffman and J. S. Shirk, Chem. Phys., 1983, 78, 331.

26 A. J. Barnes, in Matrix Isolation Spectroscopy, ed. A. J. Barnes, W. J. Orville-Thomas, A. Muller and R. Gaufres, D. Reidel, Dordrecht, 1981, p. 531.

Paper 3/03929C; Received 6th July, 1993 